Gut, 1967, 8, 301

\title{
Relationship between aspirin taking and gastroduodenal haemorrhage
}

\author{
D. J. PARRY AND PHILIP H. N. WOOD ${ }^{1}$ \\ From West Middlesex Hospital, Isleworth, and the Postgraduate Medical School of London
}

EDITORIAL COMMENT The causal relationship between aspirin and gastroduodenal haemorrhage is critically examined. Occult bleeding showed that as a group patients who had had a severe gastrointestinal bleed were not strikingly different from a group of people with normal digestive tracts. It seems likely that overt bleeding may be due to an idosyncratic response developing only in particular circumstances.

In 1938 Douthwaite and Lintott first drew attention to the association between taking aspirin and the development of major gastrointestinal haemorrhage. Later work led Hurst (Hurst and Lintott, 1939; Hurst, 1943) to suggest that aspirin was the principal cause of bleeding in at least half the 51 patients with upper gastrointestinal haemorrhage whom he had studied; in all these patients other causes of bleeding had been excluded.

In the last 10 years further attention has been directed to the coincidence of these events, and this work has been reviewed by Muir (1963). Nevertheless, the precise relationship is still not clear. The present report is concerned with the investigation of three aspects of this relationship: (1) the frequency of aspirin ingestion in a series of patients admitted to hospital consecutively; (2) aspirin taking and other aetiological factors in those patients in the series of consecutive admission who presented with overt gastroduodenal haemorrhage; (3) the possible relationship between overt haemorrhage and the occult blood loss that aspirin is known to cause in a large proportion of subjects (Wood, 1963). The results of occult bleeding studies in some of the patients in the consecutive admission series were combined with those carried out in other patients with a recent haemorrhage, and were compared with the results in patients with an acute peptic ulcer but without overt haemorrhage.

\section{ASPIRIN INGESTION BY PATIENTS ADMITTED} TO HOSPITAL

Six hundred and ninety patients admitted consecutively to two medical wards in a general hospital

${ }^{1}$ Present address: University Rheumatism Research Centre and Arthritis and Rheumatism Council Field Unit, Manchester. between April 1961 and July 1962 were questioned carefully about their use of aspirin preparations. Fifty-three patients gave unreliable answers or were unable to cooperate, and so are excluded from further consideration. The remaining 637 were classified according to whether they had taken an aspirin preparation in the week preceding admission (positive history) or had not done so (negative history).

The sex distribution of the 542 patients who showed no evidence of gastrointestinal haemorrhage was nearly equal ( $52 \%$ were male), and their ages ranged from 11 to 90 years (mean age, 57 years). Sixty-eight per cent gave a negative history and $32 \%$ a positive history, and analysis in relation to the principal disease for which they were treated revealed two patterns: (1) of the patients with cardiovascular, gastrointestinal, neurological, or haematological disorders, three out of four gave a negative history; (2) in the other diagnostic categories the distribution of patients between negative and positive groups was nearly equal.

The ages of the 95 patients admitted with overt gastroduodenal haemorrhage ranged from 21 to 94 years (mean age, 63 years), and $61 \%$ were male. The proportions in regard to aspirin taking were reversed: $31 \%$ gave a negative history and $69 \%$ a positive history. Of those with a positive history four suffered from arthritis and one was tabetic, whereas of those with a negative history one had ischaemic heart disease and one had arthritis. The remaining patients did not suffer from other diseases.

POSITIVE HISTORIES This survey thus yielded a group of 239 patients who had taken aspirin in the preceding week, of whom $142(60 \%)$ were male. The reasons for taking the drug were varied, frequently 
bore little relation to the known pharmacological effects of aspirin, and could not be linked with whether haemorrhage ensued.

Further questioning elicited the different days before admission on which the drug was taken, although it was not possible to form precise estimates of the dosage and frequency of ingestion. Table I shows the time at which aspirin had been taken. The two commonest patterns were shown by 46 patients $(19 \%)$ who had taken aspirin every day during the preceding week, and 109 patients $(46 \%)$ who took

TABLE I

TIME OF TAKING ASPIRIN BY 239 PATIENTS WITH POSITIVE HISTORIES

\begin{tabular}{|c|c|c|c|c|}
\hline \multirow{2}{*}{$\begin{array}{l}\text { Time of Taking Aspirin }{ }^{1} \\
\text { (time before admission) }\end{array}$} & \multirow{2}{*}{$\begin{array}{l}\text { Patients } \\
\text { without } \\
\text { Haemorrhage }\end{array}$} & \multicolumn{3}{|c|}{ Patients with Haemorrhage } \\
\hline & & Total & $\begin{array}{l}\text { With } \\
\text { Peptic } \\
\text { Ulcer }\end{array}$ & $\begin{array}{l}\text { With } \\
\text { Acute } \\
\text { Lesion }\end{array}$ \\
\hline
\end{tabular}

Only on one day

$0-24$ hours
$24-48$ hours
$2-3$ days
$3-4$ days
4-5 days
$5-6$ days
$6-7$ days

$\begin{array}{rr}59 & 14 \\ 21 & 6 \\ 13 & 3 \\ 15 & 1 \\ 13 & 3 \\ 2 & 0 \\ 9 & 3\end{array}$

$\begin{array}{ll}5 & 6 \\ 1 & 4 \\ 2 & 1 \\ 0 & 0 \\ 1 & 2 \\ 0 & 0 \\ 1 & 2\end{array}$

For more than one day 0-48 hours

0-3 days

$0-4$ days

$0-5$ days

0-7 days

0-8 days or more

3
6
3
0
0
30

6
2
3
1
6
10

$\begin{array}{ll}1 & 5 \\ 1 & 1 \\ 3 & 0 \\ 0 & 1 \\ 2 & 4 \\ 2 & 4\end{array}$

For more than one day, at different times

earlier than 24 hours

Totals

$\begin{array}{rr}0 & 7 \\ 174 & 65\end{array}$

4

3

23

33

${ }^{1}$ All patients were admitted within a few hours of developing symptoms and signs of bleeding. aspirin only in the 48 hours before admission. Of these, 73 (30\% of the whole group) took the drug only in the preceding 24 hours. The numbers in the different time categories are small, but do not suggest any striking difference in the pattern of ingestion between those with and without major haemorrhage.

Slightly more of the 174 patients with a positive history who showed no evidence of bleeding were male $(1 \cdot 3: 1)$, but females outnumbered males by three to one as regards habitual use of the drug, defined as taking aspirin daily for five or more days. On the other hand, habitual use occurred four times as frequently in males in the 65 patients admitted with haemorrhage, but two-thirds of them were male anyhow. No striking differences were apparent among those who took the drug occasionally.

\section{OVERT GASTRODUODENAL HAEMORRHAGE}

Most of the 95 patients with major haemorrhage were examined by gastroscopy, and in all the $p \mathrm{H}$ of the nocturnal gastric secretion was determined. A barium meal examination was made if a finite lesion was not observed gastroscopically. These investigations were carried out within a few days of admission, usually within $\mathbf{4 8}$ hours, and diagnosis was based on the result of gastroscopic and radiographic examinations. Table II records aspirin histories in relation to the causes established for the haemorrhage. In summary, 15 patients suffered from conditions that were encountered infrequently, such as hiatus hernia or carcinoma of the stomach. Six gave negative histories, and nine gave positive histories.

In 45 patients a peptic ulcer was identified. Twenty-two patients gave a negative and 23 a positive history. The similarity in aspirin histories

TABLE II

ASPIRIN INGESTION BY 95 PATIENTS ADMITTED WITH OVERT GASTRODUODENAL HAEMORRHAGE

\begin{tabular}{|c|c|c|c|c|c|c|c|c|}
\hline \multirow[b]{2}{*}{ Diagnosis } & \multicolumn{4}{|c|}{ Negative History } & \multicolumn{4}{|c|}{ Positive History } \\
\hline & Male & Female & Total & $\begin{array}{l}\text { Percentage of } \\
\text { Whole Group }\end{array}$ & Male & Female & Total & $\begin{array}{l}\text { Percentage of } \\
\text { Whole Group }\end{array}$ \\
\hline $\begin{array}{l}\text { Hiatus hernia } \\
\text { Oesophageal varices } \\
\text { Carcinoma of stomach } \\
\text { Anastomotic ulcer } \\
\text { After gastric biopsy }\end{array}$ & $\begin{array}{l}2 \\
0 \\
0 \\
0 \\
1\end{array}$ & $\begin{array}{l}1 \\
0 \\
0 \\
0 \\
2\end{array}$ & $\begin{array}{l}3 \\
\mathbf{0} \\
\mathbf{0} \\
\mathbf{0} \\
\mathbf{3}\end{array}$ & & $\begin{array}{l}0 \\
2 \\
0 \\
2 \\
1\end{array}$ & $\begin{array}{l}2 \\
0 \\
2 \\
0 \\
0\end{array}$ & $\begin{array}{l}2 \\
2 \\
2 \\
2 \\
1\end{array}$ & \\
\hline Subtotals & 3 & 3 & 6 & 6.3 & 5 & 4 & 9 & $9 \cdot 5$ \\
\hline $\begin{array}{l}\text { Gastric ulcer } \\
\text { Duodenal ulcer }\end{array}$ & $\begin{array}{l}4 \\
5\end{array}$ & $\begin{array}{l}5 \\
8\end{array}$ & $\begin{array}{r}9 \\
13\end{array}$ & $\begin{array}{r}9 \cdot 5 \\
13 \cdot 7\end{array}$ & $\begin{array}{r}2 \\
15\end{array}$ & $\begin{array}{l}4 \\
2\end{array}$ & $\begin{array}{r}6 \\
17\end{array}$ & $\begin{array}{r}6 \cdot 3 \\
17 \cdot 9\end{array}$ \\
\hline Subtotals & 9 & 13 & 22 & $23 \cdot 2$ & 17 & 6 & 23 & $24 \cdot 2$ \\
\hline $\begin{array}{l}\text { Acute gastric erosion } \\
\text { No cause established }\end{array}$ & $\begin{array}{l}\mathbf{0} \\
\mathbf{2}\end{array}$ & $\begin{array}{l}\mathbf{0} \\
\mathbf{0}\end{array}$ & $\begin{array}{l}\mathbf{0} \\
\mathbf{2}\end{array}$ & $\begin{array}{l}0 \cdot 0 \\
2 \cdot 1\end{array}$ & $\begin{array}{r}1 \\
21\end{array}$ & $\begin{array}{l}5 \\
6\end{array}$ & $\begin{array}{r}6 \\
27\end{array}$ & $\begin{array}{r}6 \cdot 3 \\
28 \cdot 4\end{array}$ \\
\hline Totals & 14 & 16 & 30 & $31 \cdot 6$ & 44 & 21 & 65 & $68 \cdot 4$ \\
\hline
\end{tabular}

'Six of these patients had a high night secretion of hydrochloric acid. 
was evident when gastric and duodenal ulcers were considered separately. The sex distribution was similar in both groups with gastric ulcers. Among the patients with duodenal ulcers, males predominated four to one in the group with a positive history, but the sex distribution was more nearly equal in the negative group.

In six patients an acute gastric erosion was observed, and all had taken aspirin in the previous week. In the remaining 29 patients no lesion was observed by gastroscopic or radiographic examination, and all except two gave a positive history; only six $(21 \%)$ of these patients were female.

It has been claimed that some formulations of aspirin are less irritant to the gastrointestinal tract than are others. It is thus of interest to note that, although aspirin in plain or compound formulation was the preparation favoured most frequently, soluble or effervescent formulations were associated with the occurrence of haemorrhage in one-fifth of the patients.

Because almost all the patients with an acute lesion had taken aspirin, the data were analysed further to try to establish the critical time of taking aspirin. This analysis had to be restricted to those patients who had taken aspirin on only one day (section I of Table I). The numbers involved are extremely small, but at 24 hours the percentages with a peptic ulcer and with an acute lesion were similar $(6.8$ and $8.2 \%$ respectively) whereas at 48 hours and at most other times the percentage with an acute lesion was greater by a factor of 2 .

\section{OCCULT GASTROINTESTINAL BLEEDING}

Occult bleeding studies were carried out using radioactive chromate, and the effects of aspirin, usually $15 \mathrm{gr}$. (1.0 g.) four times daily for five days, were observed by a standard technique (Wood, HarveySmith, and Dixon, 1962). In most of the patients with overt gastroduodenal haemorrhage the erythrocytes were labelled within a few days of the haemorrhage, and the stools were monitored until no blood loss was observed before giving the course of aspirin. Figure 1 illustrates this procedure in one patient. It has been shown that aspirin-induced bleeding in any one subject is a relatively constant and reproducible phenomenon (Croft and Wood, 1967), and so the results of provocative trials with aspirin in patients of two types were compared with those obtained in a reference sample of 226 subjects with normal digestive tracts (Croft and Wood, 1967).

PATIENTS WITH AN ACTIVE PEPTIC ULCER Twenty-six patients with a gastric ulcer and 50 with a duodenal ulcer were studied in other hospitals in an attempt to establish the susceptibility of patients with peptic ulcer disease who had not recently suffered a major haemorrhage. Thirty of these patients were male and 46 were female, and their ages ranged from 23 to 76 years (mean age, 57 years). These patients with active ulcers showed no striking difference in their range of susceptibility from the reference sample. Thirty-two per cent of those with ulcers lost blood in the range of the lowest decile of the reference sample $(<2 \mathrm{ml}$. per day of treatment $)$, and $48 \%$ were in the two lowest deciles $(<3 \mathrm{ml}$.). On the other hand, $11 \%$ of those with ulcers were in the range of the upper decile ( $>12 \mathrm{ml}$.), and $24 \%$ in the upper two deciles ( $>8 \mathrm{ml}$.). The same held true when these patients were analysed separately in relation to the site of the ulcer.

PATIENTS WITH OVERT HAEMORRHAGE Thirty-nine patients were studied who had recently suffered a gastroduodenal haemorrhage and in whom there was strong circumstantial evidence to suggest that aspirin played some role in precipitating this catastrophe. An attempt was made to study the last 23 of the 95 patients with overt gastroduodenal haemorrhage in the consecutive series questioned about taking aspirin. A number of these patients had contracted other illnesses or were unwilling to cooperate, but satisfactory studies were completed in 16 patients. The results were combined with those obtained in 23 similar patients from other hospitals. There were 19 males and 20 females, and their mean age was 54 years (range, 5-78 years).

The extremes of response are depicted in Figures 1 and 2. Figure 1 demonstrates the response in a patient who denied ever taking aspirin, apart from shortly before his haematemesis. When challenged with repeated doses of aspirin two weeks later he did not lose any blood at all. In contrast, the other patient had been taking aspirin in large doses for many years, and one day developed a haematemesis. When repeated doses of aspirin were given a few days later (Fig. 2), this patient lost $20 \mathrm{ml}$. of blood per day of treatment with aspirin, which represents a fairly extreme degree of susceptibility.

In the whole group of 39 patients, the patterns of response showed no striking difference from those seen in the reference sample (Fig. 3). Three of these patients had a gastric ulcer and five a duodenal ulcer. Even when the comparison was restricted to those with an acute gastric erosion or with no discoverable causes for the haemorrhage, the pattern of susceptibility still resembled that in the reference sample.

To follow up Croft's (1963a) suggestion that other gastric irritants might be of importance, retrospective dietary histories were obtained from the 16 


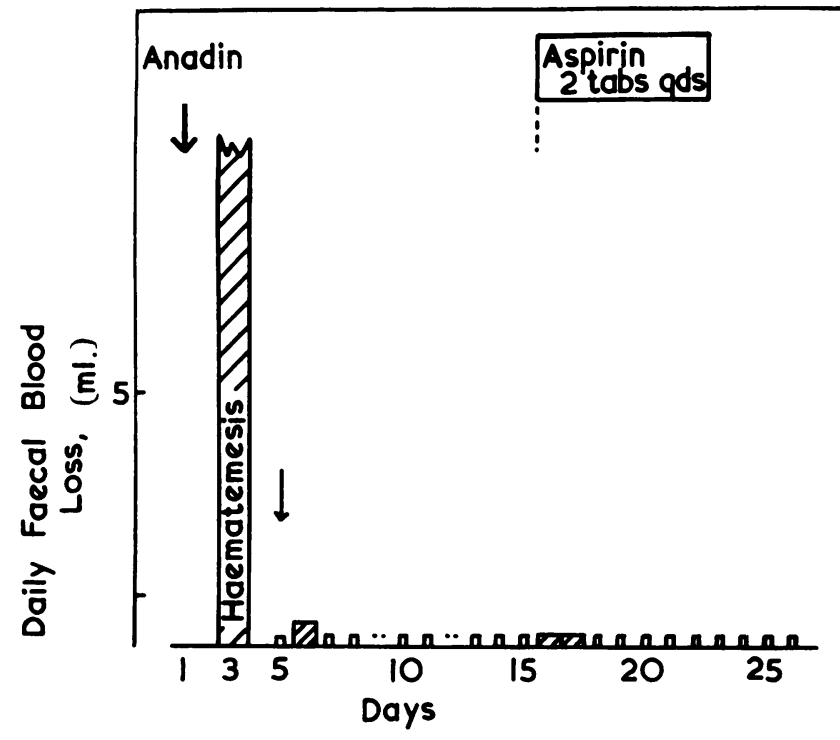

FIG. 1. Challenge with aspirin after $a$ haematemesis. A 67-year-old man with tabes dorsalis was not a habitual taker of aspirin, but one day took four tablets of Anadin to relieve lightning pains. Forty-eight hours later he had a brisk haematemesis and required blood transfusions. Gastroscopy and barium meal examination within 24 hours of admission failed to reveal a cause for the haemorrhage. On the third day in hospital his erythrocytes were labelled with radioactive chromate (indicated by an arrow), and his stools were monitored for blood loss. He showed no bleeding attributable to a standard challenge with aspirin (two tablets four times daily for seven days).

The short narrow columns indicate no blood loss, and two dots denote a day without a bowel action.

patients in the series questioned about taking aspirin. This survey yielded little information of significance, though perhaps one case history is worth recording.

A 44-year-old male Irish labourer enjoyed a Whitsun week-end of alcoholic indulgence ( 20 pints of beer), followed by attempted amelioration with four aspirin tablets. Within 24 hours he was admitted to hospital with a brisk haematemesis. No specific cause for the haemorrhage was identified, and he made an uneventful recovery. Occult bleeding studies showed that his mean loss per day of treatment with aspirin was $12 \mathrm{ml}$., and he was advised to avoid the use of the drug. One year later he suffered another haematemesis. The second haemorrhage followed an Easter week-end and the devil had done for the rest, because on this occasion he had loyally followed the advice to avoid aspirin.

\section{DISCUSSION}

In a group of 542 patients admitted to hospital without overt haemorrhage, $32 \%$ had taken an aspirin during the preceding week. Such a history was obtained slightly less frequently in women than in men, although the differences between various diseases were not great. A history of chronic use of

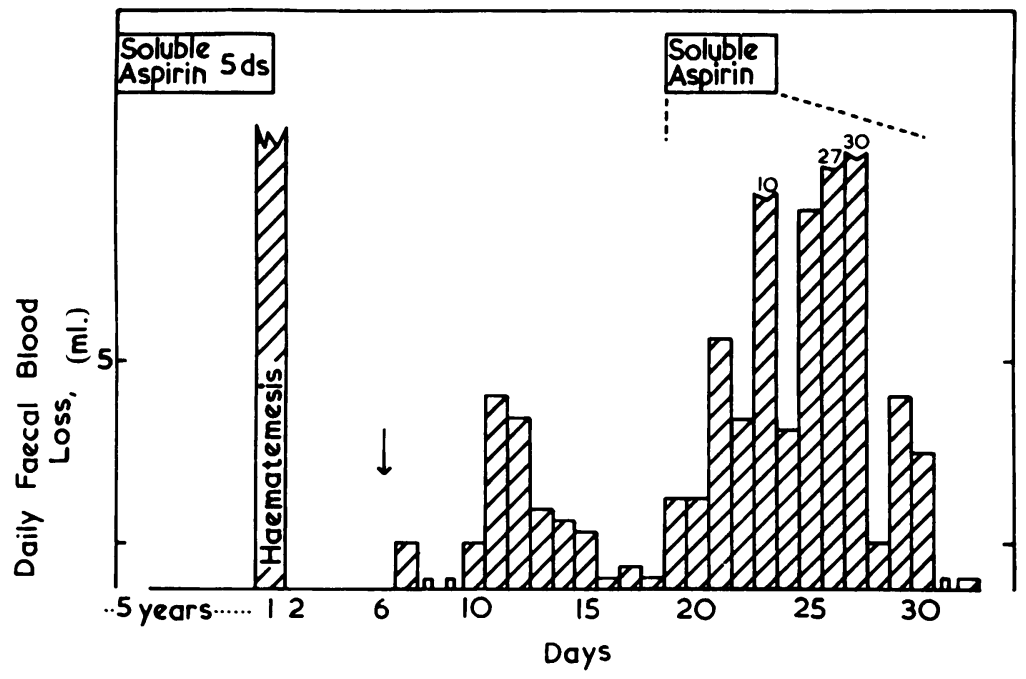

FIG. 2. Challenge with aspirin after a haematemesis. A 53-year-old woman with rheumatoid arthritis had been taking soluble aspirin five times daily regularly for five years. She developed a severe haematemesis, for which no cause could be found by gastroscopy or barium meal examination 24 hours later. Subsequent labelling of her erythrocytes and challenge with a standard course of aspirin for five days showed that she lost $20 \mathrm{ml}$. of blood per day of treatment with the drug (total loss $99 \mathrm{ml}$. blood over 11 days). Conventions as in Figure 1. 


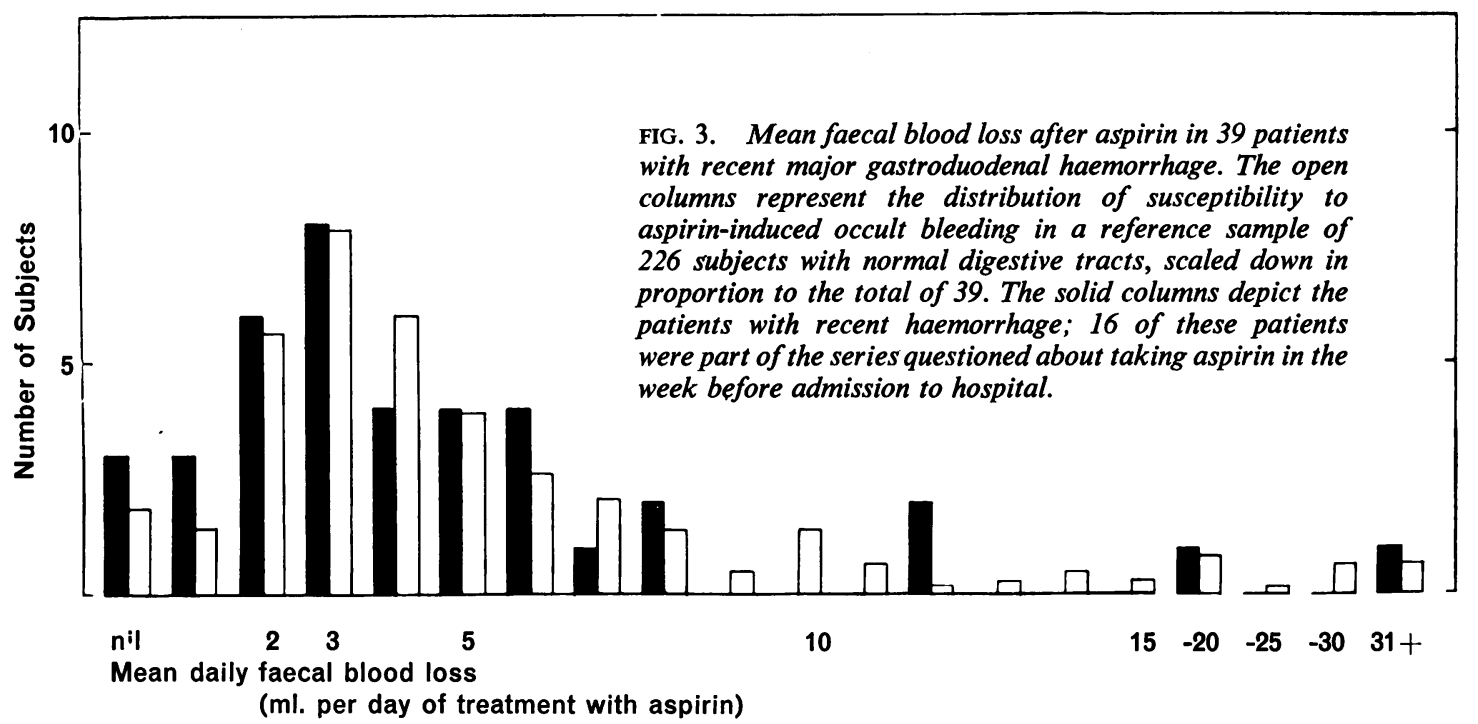

the drug was obtained more frequently from women.

Similar studies in the past have reported somewhat lower values. Thus Alvarez and Summerskill (1958) found that only $7 \%$ of out-patients had taken aspirin in the previous 24 hours, and Muir and Cossar (1959) observed that $16 \%$ of their 'control' group of in-patients had taken aspirin in the previous 48 hours. Restricting the present analysis to the same periods of time, $18.5 \%$ had taken aspirin in the preceding 24 hours and $22.5 \%$ within 48 hours. This suggests that there may be an increased frequency of taking aspirin amongst those admitted to hospital, compared with those attending an outpatient clinic.

These findings form an interesting contrast to those obtained in patients admitted with a haematemesis or melaena. When compared with the patients admitted without haemorrhage, the differences between the proportions giving a positive history were significant (peptic ulcer group, $\chi^{2} 5 \cdot 77$, $\mathrm{P}<0.02$ : acute lesion group, $\left.\chi^{2} 52 \cdot 6, \mathrm{P}<0.001\right)$. The results were similar when restricted to taking aspirin within the 48 hours before admission (peptic ulcer group, $\chi^{2} 7 \cdot 80, P<0 \cdot 01$; acute lesion group, $\chi^{2} 10 \cdot 5$, $\mathbf{P}<0.001)$. These findings accord with those in earlier studies, although the data in the acute lesion group are even more striking in the present study.

Nevertheless, such analyses yield only very crude estimates. More valuable information can be gained by restricting consideration to the patients who had taken aspirin. Amongst these patients there was little difference in the times of taking the drug and the frequency with which it was taken between those with and without a haemorrhage. Nearly one-fifth took the drug habitually, whereas almost half had recourse to aspirin only in the period immediately preceding admission to hospital. These findings suggest that the significance of the frequency of taking aspirin may be less than is suggested by the values for $\chi^{2}$.

Two important factors that affect the interpretation of these data are the dosage and frequency of taking aspirin, and the reason the drug was taken. The former could not be assessed reliably from the recollections of people who become sufficiently ill to require admission to hospital. A number of the patients with haemorrhage had taken only a single dose of one or two tablets, and this could easily cause errors in estimating the significance of the association between haemorrhage and taking aspirin.

Earlier workers (Alvarez and Summerskill, 1958) have tried to resolve whether aspirin was a precipitating factor or was taken to relieve symptoms that were more directly related to the cause of the haemorrhage. The present study was equally unsuccessful in finding a means of dealing with this problem. Lack of information on this crucial point indicates that, although aspirin ingestion is linked with the development of overt haemorrhage, there is no evidence to show that this link is necessarily of causal significance.

GASTROINTESTINAL BLEEDING A wide variety of diagnoses was established in the patients who bled. A chronic peptic ulcer was identified in slightly less than half the patients in this series, and a further $16 \%$ 
were associated with such conditions as hiatus hernia, oesophageal varices, and anastomotic ulcer.

In 35 patients no specific cause for haemorrhage was determined. Perhaps it is surprising that acute gastric erosions were seen on only six occasions. Delayed or incomplete investigation may contribute to this. In a few instances it was not possible to make a gastroscopic examination until 96 hours after admission, and this investigation was omitted in nine patients because of old age or technical difficulty due to cervical spondylosis.

Of the remaining 29 patients, six had a highly acid night gastric secretion. Although some normal people secrete a high level of hydrochloric acid during the night, it is possible that duodenal ulceration might have passed unrecognized in some of these patients. All the patients with normal gastric secretion, including those with an acute erosion, had taken aspirin during the preceding week.

The occult bleeding studies showed that, as a group, patients who have had a severe gastroduodenal haemorrhage were not strikingly different in their susceptibility to aspirin from a group of people with normal digestive tracts. The same was true for each category of patient, including those with acute erosions or no demonstrable cause, and also for patients with an active peptic ulcer, whether gastric or duodenal. The relatively constant and reproducible response to aspirin of any particular individual (Croft and Wood, 1967) was confirmed by later studies in three of the patients in this series.

A factor of potential importance is the relation between symptoms of intolerance of aspirin tablets and the development of bleeding. The nature of the intolerance is diverse, but there did not appear to be an association between any of the varieties of dyspepsia and either major or minor haemorrhage.

POSSIBLE RELATIONSHIPS The heterogeneous nature of the causes of major haemorrhage may conceal complex associations between aspirin ingestion and the development of major haemorrhage. Thus although taking aspirin is linked with haemorrhage due both to peptic ulceration and to undetermined causes, the nature of these relationships may be different. Only half the patients with peptic ulcers had taken aspirin, and in such circumstances the pathogenic role of drug taking is certainly open to question. On the other hand, all the patients with unexplained haemorrhage and normal nocturnal gastric secretion gave a positive history, suggesting that in them taking aspirin may well have been an essential link in the chain of causal events.

Aspirin is usually envisaged as a crowning insult that precipitates a haemorrhage, and Croft's (1963b) observation that exfoliation of the gastric mucosa may occur after a suspension of aspirin has been in contact with the stomach for only five minutes accords with such a view. Nevertheless, haemorrhage appeared to occur more frequently in those who had taken aspirin for 48 hours or more (section 2 of Table I) than in those who had taken the drug in only one 24-hour period (section I), such as from 0 to 24 hours $\left(\chi^{2} 6.5, P<0.02\right)$. The analyses to elucidate the crucial time of taking aspirin are of dubious worth, partly because the numbers involved are extremely small, and partly because the analysis was devised post hoc. For what they are worth, the results suggest that in the acute lesion group the significant time of taking aspirin was earlier than the last 24 hours before admission.

This suggests that apart from an immediate effect on the gastric mucosa, aspirin may have some action associated with the development of haemorrhage that is on a longer term basis. It may cause an alteration in the gastric mucosa that renders the latter susceptible to injury by agents that are normally relatively harmless, or it may produce a small acute ulcer that occasionally extends to erode the wall of a blood vessel. The data presented here are insufficient to elucidate over what period of time these changes take place, but do raise the possibility that a haemorrhage may be associated with aspirin taken some days earlier. This effect appears to be related to dosage because it is more marked in those who have taken aspirin for $\mathbf{4 8}$ hours or more. It is unlikely to be vascular in basis, as Alvarez and Summerskill (1958) showed that the transfusion requirements of patients with aspirin haemorrhages did not differ from those of patients with haemorrhage due to other causes.

The complexity of the situation is increased when it is recalled that, even if aspirin does play a causal role, it does so only in certain as yet undefined circumstances. Such a situation is demonstrated by the patient illustrated in Figure 2. This patient also raises the question of the relationship between occult and overt bleeding. The two phenomena may be unrelated, and certainly occult bleeding studies have little predictive value about susceptibility to major haemorrhage. On the other hand, the reproducibility of the occult bleeding phenomenon may represent the customary response to aspirin, an inescapable concomitant of taking the drug. Overt haemorrhage may be an idiosyncratic response developing only in particular circumstances. Such circumstances are largely unknown, although the histological changes that occur in the gastric mucosa throughout the day (Grant, Grossman, and Ivy, 1953) may be one factor, and one that accords with the impression that patients with haematemesis or melaena present most frequently at night. A more 
important factor may be the random location of the aspirin dose in the stomach. Haemorrhage may result on those occasions when the dose is situated in proximity to a larger blood vessel.

Most of the studies undertaken so far, including the present one, have been selective, restricting the enquiries to aspirin. This selectivity may have concealed other significant causal factors. Although the limited data on other gastric irritants obtained in this survey were inconclusive, the potential importance of such factors is illustrated by the patient in whom alcohol may have been responsible for one if not both haemorrhages. Brown and Mitchell (1956) incriminated alcohol in this manner in some of their patients.

The present study thus suggests that circumstantial evidence implicating aspirin as a precipitating factor in major haemorrhage should be interpreted with caution. The importance of aspirin may differ among the varying causes of major haemorrhage, and even when it does play a causative role it does so only in certain ill-understood circumstances. One is left with the impression that the patients at greatest risk are those who cannot be protected, the patients without recognizable pathology in the gastrointestinal tract. To question the wisdom and ethics of medication with aspirin in these circumstances requires that one depart from premises based on reason and knowledge.

\section{SUMMARY}

Six hundred and thirty-seven patients admitted consecutively to two medical wards of a general hospital were questioned about taking aspirin. Of the patients without haemorrhage, $32 \%$ gave a positive history, whereas $69 \%$ of those admitted with a major haemorrhage had taken aspirin in the previous week.

Among the patients who had taken aspirin, the times of taking the drug and the frequency with which it was taken were similar in both groups of patients, those with and without a haemorrhage, suggesting that the significance of the frequency of aspirin taking may be less than is indicated by the crude incidence data.

In more than one-third of the patients admitted with overt haemorrhage no specific cause could be determined. Nearly all these patients had taken aspirin, and it is in this group that aspirin may play an essential causative role. Peptic ulcer disease accounted for almost half the instances of haemorrhage, but the role of aspirin in these patients was less definite.
Studies of aspirin-induced occult bleeding showed that the susceptibility of patients with active peptic ulcers or with recent haemorrhage due to any cause did not differ significantly from that of patients with normal digestive tracts.

The nature of the possible effects of aspirin is discussed, and other factors contributing to the development of haemorrhage are reviewed.

It is concluded that the patients at greatest risk from this effect of aspirin are those who cannot be protected, patients without recognizable pathology in the gastrointestinal tract.

We are indebted to Dr. N. F. Coghill for much encouragement and help, to Dr. F. M. Abeles and Dr. D. H. Bodger for most of the radiographic studies, to Mr. Michael Curwen and Mr. Seymour Kantor for advice, and to Miss Pamela Coates for technical assistance. We are grateful to Dr. Coghill, Dr. Allan St. J. Dixon, and the medical staff at the Hammersmith Hospital for the opportunity to study patients under their care. We wish to acknowledge the cooperation of the patients who participated in this study. One of us (P.W.) was in receipt of a research fellowship from the Nicholas Research Institute.

\section{REFERENCES}

Alvarez, A. S., and Summerskill, W. H. J. (1958). Gastrointestinal haemorrhage and salicylates. Lancet, 2, 920-925.

Brown, R. K., and Mitchell, N. (1956). The influence of some of the salicyl compounds (and alcoholic beverages) on the natural history of peptic ulcer. Gastroenterology, 31, 198-203.

Croft, D. N. (1963a). Discussion on aspirin. In Salicylates, An International Symposium, edited by A. St. J. Dixon, B. K. Martin, M. J. H. Smith, and P. H. N. Wood, p. 241. Churchill: London.

(1963b). Exfoliative cytology of the stomach after the administration of salicylates. Ibid., pp. 204-212.

- , and Wood, P. H. N. (1967). Gastric mucosa and susceptibility to occult gastrointestinal bleeding caused by aspirin. Brit. med. J., 1, 137-141.

Douthwaite, A. H., and Lintott, G. A. M. (1938). Gastroscopic observation of the effect of aspirin and certain other substances on the stomach. Lancet, 2, 1222-1225.

Grant, R., Grossman, M. I., and Ivy, A. C. (1953). Histological changes in the gastric mucosa during digestion and their relationship to mucosal growth. Gastroenterology, 25, 218-231.

Hurst, A. (1943). Aspirin and gastric haemorrhage. Brit. med. J., 1, 768.

-, and Lintott, G. A. M. (1939). Aspirin as a cause of haematemesis: a clinical and gastroscopic study. Guy's Hosp. Rep., 89, 173-176.

Muir, A. (1963). Salicylates and the gastrointestinal tract. In Salicylates, An international Symposium, edited by A. St. J. Dixon, B. K. Martin, M. J. H. Smith, and P. H. N. Wood, pp 187188. Churchill: London.

-, and Cossar, I. A. (1959). Aspirin and gastric haemorrhage. Lancet, 1, 539-541.

Wood, P. H. N. (1963). Studies of occult bleeding caused by salicylates and related compounds. In Salicylates, An International Symposium, edited by A. St. J. Dixon, B. K. Martin, M. J. G. Smith, and P. H. N. Wood, p. 194. Churchill: London.

- Harvey-Smith, E. A., and Dixon, A. St. J. (1962). Salicylates and gastrointestinal bleeding: acetylsalicylic acid and aspirin derivatives. Brit. med. J., 1, 669-675. 